\title{
Students' Experiences of Online English Language Learning by Using YouTube
}

\author{
Adriadi Novawan* \\ English Department \\ Politeknik Negeri Jember \\ Jember, Indonesia \\ novawan@polije.ac.id
}

\author{
Susan Mila Alvarez-Tosalem \\ College of Arts and Sciences \\ University of the Philippines Visayas \\ Iloilo, Philippines \\ satosalem@up.edu.ph
}

\author{
Titik Ismailia \\ English Department \\ Politeknik Negeri Jember \\ Jember, Indonesia \\ titik@polije.ac.id
}

\author{
Julien Arief Wicaksono \\ English Department \\ Politeknik Negeri Jember \\ Jember, Indonesia \\ julien_arief@polije.ac.id
}

\author{
Rimbi Budi Setiarini \\ Department of Management \\ STIE Mandala \\ Jember, Indonesia \\ rimbibudi@gmail.com
}

\begin{abstract}
This pandemic situation stimulates transformation of educational programs worldwide. Right now, English Language Teaching programs are transforming most of the onsite activities into remote learning which involve synchronous and asynchronous learning and communication. One of the popular technologies for teaching and learning English is YouTube. For most of the Web 2.0 generation, YouTube provides users with learning resources that offer communicative features effective for both synchronous and asynchronous learning. However, the extent to which YouTube has been used and experienced by tertiary students in specific contexts during this pandemic situation has yet to be explored to inform policy and practices of EFL education. This research draws from the results of a case study that employed questionnaire and open-ended interviews conducted among university students in an Indonesian locale. The findings indicate that YouTube was popularly used in current online EFL classrooms. The students' experience revealed positive attitude toward the use of YouTube in EFL learning. Nevertheless, it was not as frequently used for other purposes such as entertainment and learning other subjects. At the same time, potential drawbacks were identified to inform improvement of teaching and learning practices in future.
\end{abstract}

Keywords - English as a foreign language, remote learning, YouTube, students' experience

\section{INTRODUCTION}

Before the spread of corona viruses in many countries around the world, the use of technology such as computers, smartphones, and the internet for English as a Foreign Language (EFL) teaching and learning has significantly been developed and studied. As social and physical distancing policies were implemented globally to mitigate the viruses' transmission, online and distance learning activities have massively flourished to ensure that education continues. Moreover, formal education which is commonly predominated by onsite programs, is now transforming itself into remote and online programs in adherence to the health protocols. Policy makers, educational leaders, and EFL educators have been working together to make online teaching and learning possible, in spite of many technical and support limitations. In order to cope with the online learning programs, families have been trying to adjust with their children at home. Therefore, the demand for electronic devices, information technologies, computer and smartphone applications, as well as the internet, has increased dramatically.

In the context of this development, the dynamic practices of online EFL teaching and learning employ different electronic learning devices (e.g. laptop, computer, tablet, smartphone), platforms (LMS, Web 1.0, Web 2.0, social media, etc.), and resources (e-library, e-journal, e-database, enewspaper, e-images, videos). Today's information technology makes possible the unlimited elaboration between and among particular devices, platforms, and resources. The elaboration varies depending on each situation, facility/infrastructure, curriculum setting, instructional purposes, and how English language teachers and instructors design online teaching and learning.

One of the popular platforms and resources for learning English is YouTube. As one of the Web 2.0 generation [1], it provides users not only with rich learning resources that are easily linked with other platforms, but also the synchronous and asynchronous communicative features which allow them to interact with each other in various ways. However, with the onset of the pandemic, there is a need to investigate how YouTube has been used in online EFL learning to inform course design refinements. In particular, investigation is necessary in the context of high-risk environments where learning is severely affected by the spread of corona virus. In normal learning environments, EFL classes use technologies, including YouTube, in multimedia-based classrooms or in laboratories with the requisite infrastructure, networks and technical support. Due to the pandemic, everything changed dramatically since all learning activities had to be done from home. Both teachers and students face the huge challenge of sustaining technology-enhanced EFL learning albeit remotely. In this study, the students' perspectives were explored to identify their experience and challenge of EFL learning with the use of YouTube. 


\section{A. CALL and MALL}

Earlier development of online language learning has been influenced by Computer-Assisted Language Learning (CALL) theories. CALL is understood as a process of learning that utilize computers which improve students' language ability [2]. Other acronyms used to signify the similar notion are Web-enhanced Language Learning (WELL), Computer Applications in Second Language Acquisition (CASLA), and Technology-enhanced Language Learning (TELL) [3]. In general, CALL offers a stable system that includes electronic infrastructures and networks, which are installed in rooms or laboratories, to support language teaching and learning processes. CALL includes issues of materials design, technologies, pedagogical theories and modes of instruction [2].

From time to time, digital technology has transformed mobile devices into more sophisticated learning tools which offer flexibility and accessibility to learning processes. There have been enormous innovative efforts under the theories of Mobile-Assisted Language Learning (MALL) which suggest a movement from CALL to MALL without undermining the underpinning role of the former [4]. Among various types of mobile devices, smartphone has gained its popularity because its flexibility for daily use [5]. Continuous studies have confirmed its role and function in support of the teaching and learning of EFL. MALL has been identified to support the development of students' English language skills through formal and informal ways [6]. Studies investigated the students' experience of EFL mobile-learning and have confirmed the impact of MALL on students' motivation and learning habit [7]. A study [6] that reviewed the literature on MALL from 2012 to 2016, showed that mobile technologies have been found to afford flexibility and continuity of use which enable timely feedback, personalization, socialization, self-evaluation, active participation, peer coaching, sources of inspiration outdoors and cultural authenticity. Since it provides the students with ease and flexibility for everyday use, teachers can further explore how to create daily authentic learning situations for the development of students' social skills [8].

Both CALL and MALL have undergone significant development due to the flourishing studies and researches in the field of TESOL and SLA until recently. Both focus on the students' learning process which challenges the language teachers to pay more attention to designing the on-site and online circumstances that promote English language proficiency.

Moreover, studies and researches in CALL and MALL in turn strengthen the theoretical frameworks of both theories and open a wide opportunity to meet and elaborate one from the other, in particular, in terms of technological circumstances and pedagogical approaches. Many e-learning platforms which were designed for access through computer and internet networks operated and situated in rooms and laboratories, may now be accessed and operated on tablets and smartphones. Even some basic administrative functions may be managed on tablets and smartphones. For the administrators of online language teaching, the elaboration between CALL and MALL offers more sophisticated impacts on teaching process to cater to different learning needs and purposes. Now, there are many LMS-based e-learning platforms which can flexibly be administered and accessed through computers, tablets, and smartphones such as Moodle, Chamilo, Open edX, Blackboard Learn, and Canvas. Moreover, social communication applications which were first designed for tablets and smartphones at the onset, have now extended their functionalities to work on laptops and computers, such as WhatsApp, Instagram, and Twitter.

In the context of these developments, the learning sources and resources are immensely available electronically in databases and online libraries which collect and manage many kinds of documents such as e-books, e-articles, magazine, newspapers, image, audio and music, podcast and video, movie, and templates for making e-booklets, e-posters, power point presentation, and others. All of these sources are easily accessed, used, elaborated, and linked with each other through specific LMS platforms. One of these popular learning resources is YouTube.

YouTube collects all kinds of videos with unlimited themes which are uploaded by its users for various purposes, either individually, collectively, or institutionally. This unlimited source is possible because YouTube allows each user to upload and manage their own channel on YouTube. The users feel happy and appreciated when their channels are visited and subscribed to by many viewers. The total number of monthly active YouTube users currently reaches approximately 2 billion with 1 billion videos watched every day [9].

However, it also opens the possibility to get videos with a wide range of quality from very poor to excellent one. Right now, YouTube has become the biggest video library which offers viewers with whatever they want to know, watch, and learn, including those about English language learning. YouTube is popular among educators and students in the context of English Language Learning. There are thousands of videos uploaded on YouTube to provide sources for those who want to learn English in all levels.

\section{B. YouTube}

YouTube, since its first inception in 2005 has undergone a rapid development of its services. At this time, it allows the users to take the role of viewers and active users or youtubers. Viewers are those who visit and watch videos with or without signing into their account. They may watch YouTube videos for the purpose of entertainment, doing hobbies, learning, and other social purposes. This does not require one to have an account and sign in. But when they have an account and sign into it, they may access YouTube more conveniently. Moreover, YouTube offers a challenging opportunity for their users to be more than just viewers called youtubers. As a youtuber, the users can create their own channel and organize their own videos as a YouTube partner. When they fulfilled some YouTube requirements, youtubers can have an opportunity to get salary from their channel's performance.

YouTube has developed many creative and innovative features for its users, which can be applied for many different purposes and services, depending on two categorizes: free and paid (premium) membership. What is addressed in this paper is free membership on YouTube. Through free membership, YouTube has in a way contributed to the online and distance teaching and learning agendas. This may be in terms of delivery, teaching resources, interactions, data storage, and even channel management that enables the users to manage their channel and videos flexibly. 
1) Live streaming: One of the fantastic features offered by YouTube is live streaming which allows the users to create a live event or webinars which can be recorded for many purposes, and categorized either as public, non-public, or private. This feature allows English teachers and lecturers to make their teaching lively, while their students are at the same time learning from experts from different places. While doing live teaching and learning on YouTube, the participants may still interact with the teacher and other participants through the chat section. The students' attendance on YouTube Live Streaming class can also be monitored and recorded on the chat section.

2) Video upload: For those who prefer a more planned, prepared, and delayed teaching delivery, teachers will find the video upload feature useful and convenient. In this way, teachers will have more time to record and edit their videos before uploading on YouTube. This feature makes possible the inclusion and insertion of texts, images, or clips to help the students understand the video materials better. Moreover, after the video is uploaded, the teacher can save it privately, to be edited again on YouTube without making it public. In this case, only the owner of the account can watch the video. When the video is ready, it can be launched anytime in different options: public, unlisted, scheduled, and premiered. When the uploader selects public, the video will directly go to public or anyone can see and watch it. By choosing the unlisted option, the uploader may only choose specific people wo can watch it. In many cases, teachers can simulate actual classrooms. By selecting scheduled, they can plan the exact date and time when the public can watch the video. Similarly, by choosing premiered, teachers can create an elegant way of starting their class which allows the viewers (students) to wait and count together until the video starts.

3) Video Collection: If users opt not to create their own channel, they may still have the opportunity to create their collection which can be easily personalized for specific purposes. They can make many collections, categorize these into particular areas of interest, and align with their needs. For teaching and learning purposes, both teachers and students can easily organize their teaching and learning resources by managing their playlists.

4) Customized comments: Besides the two features aforementioned, YouTube also provides users with interactive tools through the comments section, which can be customized when uploading a video or shifting to live streaming. In English language teaching contexts, the comments section may be used as an interactive communication and feedback. Moreover, it can be used to teach writing, as in the following instances: making a short summary, writing a short reflective essay, giving a written opinion, answering questions/issues given on the lecture, responding to other comments, and leaving a link of assignment submissions in the form of file, audio, video, blog, etc. In this way, YouTube offers many options related to course design and management. Qualitative Grading is also possible by using the emoticon of thumbs down for poor, thumbs up for good, and heart for excellent. However, in terms of commenting features, obedience to YouTube guidelines is also crucial.

5) Easy for cross-referencing: Other features offer users the opportunity to refer to and elaborate other videos on YouTube and other electronic sources. This feature helps teachers to create comparative and constructive elaboration on particular topics addressed in the uploaded video. Discussions can be initiated by linking or bringing in the refereed sources into the forum. In this manner, YouTube is able to provide more comprehensive learning than an onsite class.

6) Opportunity and restrictions: Using YouTube can provide a huge opportunity for EFL students to learn English interestingly and meaningfully. However, YouTube regulations have to be strictly followed by its users. Failure to comply with the regulations can have impacts on restrictions through visibility of the videos, channels, and account suspension. The first category is called monetization. YouTube users have the opportunity to be a YouTube partner by fulfilling the requirements of monetization. In this category, failure to adhere to the requirements can lead to visibility and channel suspension, depending on each case. The second category is visibility requirements which will lead to visibility suspension of specific videos that ignore or violate particular guidelines. The third is channel and account requirements. Heavier and repeated violations may result in account suspension. This creates opportunity, but at the same time, gives restrictions for language educators in designing online teaching, as they have to abide by YouTube regulations.

\section{Students' experience of using YouTube}

The expected outcomes of using YouTube in EFL learning have been identified in many studies. YouTube has been found to be a useful tool to facilitate language teaching that can improve confidence and afford authentic student-centered learning with increased participation [1]. Studies have shown that by using YouTube, EFL teachers can help students to develop their pronunciation, listening, speaking, and writing skills [10][11][12][1][13][14][15]. The features offered by YouTube provide the opportunity for teachers to create authentic learning [11][1] while for the students, its potential can provide countless hours of exposure to spoken English [10].

There are various possibilities on how to use YouTube for EFL teaching and learning. For both teacher and the students, YouTube may be employed as teaching and learning media, resource or materials, and communication tool. Its flexibility allows its integration within different pedagogical frameworks, ranging from traditional to learner-centered, thereby promoting learner autonomy [12]. Another reason for YouTube's prominence for EFL teaching is that it allows for ubiquitous teaching and learning activities without the limitation of time and room. Moreover, YouTube features provide students with video collection opportunities that can be used as personalized and customized e-library. In the case of teachers, the opportunity to create videos and upload these through YouTube can become a radical way to curating language teaching resources. It provides students with optimum linguistic input and at the same time encourages 
them to engage sufficiently with the target language [13]. Furthermore, YouTube videos may be accessed easily by students, as it does not require so much in terms of data/bandwidth.

\section{METHODS}

\section{A. Participant}

The research participants were tertiary students enrolled in the English Language Course at several universities in Indonesia. There were 159 participants who filled out the questionnaire voluntarily and 12 of them signified their willingness to continue their responses through video call interviews. Since the university curriculum in Indonesia generally offers the English Subject(s) in the first and second year levels, the target respondents for this case study were first and second year students.

\section{B. Data Collection}

In collecting the data, a questionnaire and interview were used to gather students' perception and experiences of using YouTube. The questionnaire was designed to gather general information about their experience of using YouTube comprising of 8 close-ended questions. While the interviews were done to deepen the information on specific experiences of using YouTube in learning English, particularly their perception on skill improvement obtained, and expectation.

\section{Data Analysis}

The data collected from the questionnaire and interviews were analyzed descriptively to expose the students' perception, experience and expectation related to using YouTube in English language learning.

\section{RESULTS AND DISCUSSION}

\section{A. The results of the questionnaire}

The participants' profile: The participants were tertiary students of some local universities in Indonesia. The questionnaire was created on Google Forms and shared through social media platforms and emails. As many as 159 participants voluntarily filled out the questionnaire. $77.4 \%$ of them (123 participants) were female and $22.6 \%$ (36 participants) were male university students. The participants were studying different majors and had completed or were enrolled in English Language Courses at their universities, as presented in Table 1.

TABLE I. MAJOR OF STUDY

\begin{tabular}{lcc}
\hline Department & Number & Percentage \\
\hline English & 39 & 62 \\
Informatic Engineering & 17 & 10.7 \\
Public Accountant & 37 & 23.3 \\
Midwifery & 43 & 27 \\
\hline
\end{tabular}

The questionnaire consists of 8 questions related to the participants' experience and behavior of using YouTube for personal, general, and academic purposes.

The questions:

1. Do you like using YouTube?

2. How often do you access YouTube? (YT)

3. How often do you access YouTube for entertainment? (ET)
4. How often do you access YouTube for learning English? (LE)

5. How often do you access YouTube for learning others? (LO)

6. How often are you selective by considering the specific purpose or targets when using YouTube? (Sel)

7. How often do you create and upload your own videos on YouTube?

8. What topic did you or will you choose when uploading your own video on YouTube?

In answer to question No. 1, majority of the participants $(89.3 \%)$ expressed their preference for using YouTube regardless of the purpose. $1.9 \%$ of the participants chose "No", while $8.8 \%$ were in doubt (see Table 2). The data show us how popular YouTube is among the research participants in the local context.

TABLE II. PREFERENCE FOR USING YOUTUBE

\begin{tabular}{lcc} 
Answer & Number & Percentage \\
\hline Yes & 142 & 89.3 \\
No & 3 & 1.9 \\
May be & 14 & 8.8 \\
\hline
\end{tabular}

More specifically, in answer to questions No. 2 to No. 6 related to the frequency of using YouTube for various purposes, the data are presented in Table 3.

TABLE III. FREQUENCY OF USING YOUTUBE FOR VARIOUS PURPOSES

\begin{tabular}{ccccccccc}
\hline $\begin{array}{c}\text { Question } \\
\text { Number } \\
\text { /Code }\end{array}$ & $\begin{array}{c}\text { Almost every } \\
\text { time }\end{array}$ & $\begin{array}{c}\text { Almost every } \\
\text { day }\end{array}$ & \multicolumn{2}{c}{$\begin{array}{c}\text { Twice or } \\
\text { three times a } \\
\text { week }\end{array}$} & \multicolumn{2}{c}{$\begin{array}{c}\text { Never in } \\
\text { these late } \\
\text { months }\end{array}$} \\
\cline { 2 - 10 } & $\boldsymbol{n}$ & $\%$ & $\boldsymbol{n}$ & $\%$ & $\boldsymbol{n}$ & $\boldsymbol{\%}$ & $\boldsymbol{n}$ & \% \\
\hline 2/YT & 25 & 15.7 & 103 & 64.8 & 30 & 18.9 & 1 & 0.6 \\
\hline 3/ET & 26 & 16.4 & 99 & 62.3 & 34 & 21.4 & - & - \\
\hline $4 / \mathrm{LE}$ & 7 & 4.4 & 37 & 23.3 & 102 & 64.2 & 13 & 8.2 \\
\hline 5/LO & 16 & 10.1 & 72 & 45.3 & 69 & 43.4 & 2 & 1.3 \\
\hline 6/Sel & 59 & 37.1 & 70 & 44 & 28 & 17.6 & 2 & 1.3 \\
\hline 7/Act & - & - & 12 & 7.5 & 75 & 47.2 & 72 & 45.3 \\
\hline
\end{tabular}

As shown in the table, particularly on the extent to which the participants accessed YouTube in their daily activities (No 2/YT), the survey indicated that $64.8 \%$ of the participants accessed YouTube almost every day, $18.9 \%$ accessed it twice or three times a week, $15.7 \%$ used it almost every time, and only $0.6 \%$ did not use it in previous months.

Related to the entertainment purpose (No 3/ET), $16.4 \%$ of the participants accessed YouTube almost every time for entertainment. The majority $(62.3 \%)$ of them accessed YouTube for entertainment almost every day, and $21.4 \%$ of them were twice or three times a week. No one chose the option Never in these late months which indicated that all of the participants used YouTube on a regular basis; either daily or weekly.

The data indicated that most of the participants $(64.2 \%)$ accessed YouTube for learning English (No 4/LE) twice or three times a week. 23.3\% enjoyed YouTube for learning English almost every day and $4.4 \%$ almost every time. The remaining $(8.2 \%)$ did not use YouTube for learning English in the consequent months. Different from that of learning English, the majority of the participants $(45 \%)$ accessed YouTube for learning other subjects almost every day, $43.4 \%$ 
did it twice or three times a week, $10.1 \%$ almost every time, and $1.3 \%$ did not access YouTube for learning other subjects in previous months (No 5/LO).

The question No 6/Sel was intended to investigate the manner of the participants when using YouTube. The biggest percentage $(44 \%)$ chose selective almost every day, followed by those who were almost selective every time (37\%), and lastly, twice or three times a week selective (17.6\%). The smallest percentage (1.3\%) chose the option never selective in previous months.

The question No 7 basically investigated to what extent did the research participants play a role as YouTube users which may signify how familiar they were in organizing their activities on YouTube. The data in Table 4 indicated that 7.5 $\%$ of them, who were categorized into active users of YouTube, uploaded their videos almost every month. Most of them $(47.2 \%)$ uploaded their videos on YouTube several times a year, on the other hand, $45 \%$ were not familiar with uploading videos on YouTube, at least in previous years.

TABLE IV. FREQUENCY OF USING YouTube For VARIOUS PURPoSES

\begin{tabular}{ccccccccc}
\hline $\begin{array}{c}\text { Question } \\
\text { Number } \\
/ \text { Code }\end{array}$ & $\begin{array}{c}\text { Almost every } \\
\text { week }\end{array}$ & $\begin{array}{c}\text { Almost every } \\
\text { month }\end{array}$ & $\begin{array}{c}\text { Twice or } \\
\text { three times a } \\
\text { year }\end{array}$ & \multicolumn{2}{c}{$\begin{array}{c}\text { Never in } \\
\text { these late } \\
\text { years }\end{array}$} \\
\cline { 2 - 10 } & $\boldsymbol{n}$ & $\%$ & $\boldsymbol{n}$ & $\%$ & $\boldsymbol{n}$ & $\%$ & $\boldsymbol{n}$ & $\%$ \\
\hline 7 & - & - & 12 & 7.5 & 75 & 47.2 & 72 & 45.3 \\
\hline
\end{tabular}

In answer to question No 8 , the biggest percentage of the participants (43.4\%) chose to upload the videos related to their education, learning, and assignment, $27.7 \%$ chose entertainment videos, and $14.5 \%$ others which were not mentioned on the options. Surprisingly, only $9.4 \%$ of chose topics related to event, program, or trip, and $5 \%$ about relations such as friendship and family (Table 5).

TABLE V. TOPICS OF VIDEO TO UPLOAD ON YOUTUBE

\begin{tabular}{lcc}
\hline Answer & Number & Percentage \\
\hline Education/Learning/ & 69 & 43.4 \\
Assignment & 15 & 9.4 \\
Event/program/trip & 8 & 5 \\
Relations & 44 & 27.7 \\
Entertainment & 23 & 14.5 \\
\hline Others & & \\
\hline
\end{tabular}

\section{B. The results of interviews}

TABLE VI. THE INTERVIEW PARTICIPANTS PROFILE

\begin{tabular}{ccccc}
\hline No & Participants & Gender & Major & Year \\
\hline 1 & Student 1 & F & Midwifery & $1^{\text {st }}$ \\
2 & Student 2 & F & Midwifery & $1^{\text {st }}$ \\
3 & Student 3 & F & Midwifery & $1^{\text {st }}$ \\
4 & Student 4 & F & Midwifery & $1^{\text {st }}$ \\
5 & Student 5 & F & Midwifery & $1^{\text {st }}$ \\
6 & Student 6 & M & Informatic & $2^{\text {nd }}$ \\
7 & Student 7 & F & Informatic & $2^{\text {nd }}$ \\
8 & Student 8 & M & Informatic & $2^{\text {nd }}$ \\
9 & Student 9 & F & Accountant & $2^{\text {nd }}$ \\
10 & Student 10 & M & English & $2^{\text {nd }}$ \\
11 & Student 11 & F & English & $2^{\text {nd }}$ \\
12 & Student 12 & F & English & $2^{\text {nd }}$ \\
\hline
\end{tabular}

The participants' profile: The interviews were done voluntarily to 12 participants by using video calls. Each of the participants was given at least three open-ended questions with many probing questions to close-in on their actual experience of learning by using YouTube and what kinds of impact they perceived.

1) How did you feel when learning English with the use of YouTube videos?

The interview revealed that many English teachers used YouTube to function as either the teaching media or learning resources. As a medium, YouTube became a tool for teachers' pedagogical approach in facilitating online teaching and learning. While as a resource, it provided the students with the English language materials to learn. Based on the interviews, YouTube was used in two different ways:

- As main media or resource

- As additional/accidental media or resource

When used as the main media, the lecturers planned, implemented, and evaluated the teaching and learning process with the use of YouTube. They created and managed their own channel for teaching purposes based on the curricular offering. In this case, the students had the opportunity to create and manage their channel for learning and assignment submissions. Other platforms were also used to complement YouTube depending on the instructional needs. Some participants expressed their excitement towards participating in the learning process and assignment submissions, with YouTube as the main media or resource. The activities were useful because they had the opportunity to learn English by actualizing themselves through English on YouTube.

"My English teachers used YouTube to deliver their lectures and asked us to upload the assignments on YouTube. ... We were asked to organize our channel consisting of our assignments. I am happy because I can make my own channel on YouTube." (Student 12)

"I feel that the assignments were difficult. I had to learn myself many things about YouTube (sic). .... But, of course, I learned new things. I like making my own video and uploading it on my channel." (Student 9)

Alternatively, the use of YouTube as an additional media or resource entailed its occasional or accidental use in the learning process. The teachers might use other platforms in planning, implementing and evaluating the teaching and learning process. In this case, the frequency of students being exposed to YouTube videos was not as much as the former. However, the participants indicated similar findings which show that they like watching and doing learning activities by using or creating videos. Students used YouTube not only to access the videos recommended by their lecturers, but also to access other videos relevant to the topic. This allows them to learn more deeply by comparing and cross-referencing the materials from their lecturers with other related materials from other videos.

"YouTube is interesting because it has so many videos. Sometimes, when I accessed the link given by my teacher, I spent more time to watch even more videos with the same theme just to compare. By comparing, I learned better. (Student 3)

2) How did you perceive improvement in learning English with the use of YouTube? 
All interview participants showed positive experience with YouTube. Some participants confidently expressed that learning with YouTube was not only practical but also innovative in improving students' English skills. Other technologies were also used either to complement YouTube or conversely, YouTube complemented other platforms. Those who expressed great confidence in YouTube's impact on language learning were those who indicated particular traits related to motivation and autonomy.

"I learned about how to study English better and I practiced the clues... I got improved (sic) in my listening, vocabulary, grammar, and I like watching the common grammatical errors recommended by my teacher." (Student 6)

"I frequently learned English by using YouTube videos... I like watching English conversations, songs, and movies on YouTube. And I feel that I can listen and speak much better than before." (Student 12)

"I think yes. I like YouTube and spent much time to practice my English. Now I have a lot of vocabularies to use in speaking and writing. So, it is becoming a bit easier now." (Student 10)

3) What are your expectations from your lecturer in their use of YouTube for teaching English?

The participants also expressed their expectations related to the quality of online English Language Teaching through YouTube. Their responses discussed the following dimensions: quality teaching, various uses of technology, flexibility and support.

a) Quality teaching: Quality teaching has always become the students' expectation in all educational programs. Quality online teaching is influenced by the extent to which the lecturer performs the following: careful planning, relevant materials development, engaging teaching method, and appropriate assessment. The findings revealed the participants' expectations related to the above issues.

"I hope my lecturer could prepare the online lesson better, and provide us with the best materials, of course. And we also need the lesson is delivered (sic) interestingly, not monotonous." (Student 10)

"I am not so clear about how were we evaluated during the teaching process. We were given a lot of assignments, but we did not receive any feedback. I didn't know exactly my lecturer's standard." (Student 1)

"Sometimes I feel that my teachers did not give us the relevant, interesting videos. Maybe because they did not really select it and maybe, I don't know. Maybe they had their own consideration, I don't know." (Student 4)

More specifically, some findings indicated the participants' expectation related to lecturers' professionalism in creating and managing their teaching through their YouTube channels.

"I know that many people and students are becoming YouTubers. I mean, I know that lecturers are not YouTubers, but if they have a great learning channel, it can be so wonderful." (Student 8)
"I have subscribed (sic) some good English learning channels. And they frequently updated new videos which are very quality. Maybe, our lecturers can also create a good channel to learn English." (Student 11)

"We can find anything we want on YouTube. I hope that my lecturers can create their own videos which are excellent and interesting. (Student 7)

b) Various uses of technology: Online learning involves the use of various technologies relevant for learning. The lecturers were expected to use more than one technology as expressed below.

"In my opinion, there are many websites, applications or software, and others which can be used to teach English. Because merely using YouTube can be boring. (Student 1)"

"Maybe, not all learning activity (sic) can be done with YouTube. I actually like reading novels and I cannot do that on YouTube." (Student 10)

"I think YouTube is not enough. I will get easily bored if my lecturer only uses ( sic) it in teaching. It will be great if my lecturer use (sic) various types of technology." (Student 2)

As revealed above, employing YouTube for English Language Teaching could be both useful and fruitful, albeit still considered insufficient as a stand-alone medium/resource to ensure the effectivity of the learning process. YouTube offers some wonderful features for learning communication skills which can effectively motivate the students. However, without being well-designed and elaborated with other relevant technologies in light of a particular educational framework, the expected effects on the students' motivation and achievement development can be trivial. These pose another challenge for the lecturers as they need to learn how various technologies can be used for specific teaching such as that of vocabulary, grammar, and the four skills, both integrated and separated.

c) Flexibility and support: Flexibility in this context was in connection with the course policies and technical issues such as teaching modes, media used, attendance, assignment submission, and other issues related to technical support and network. In the online teaching and learning process, there are many technical factors that need to be handled carefully. It is common that because of some technical problems, the synchronous teaching and learning process is disturbed or interrupted which may hinder an individual student or a group of students, even the whole class from the expected outcomes. Therefore, flexibility was considered necessary by the interview participants.

"I have friends who live in the remote areas (sic). They have to find the nearest place from home which will give them the internet access in order to be able to join courses." (Student 4)

"I have ever (sic) experienced many times being late. Sometimes I didn't attend the online classes because of the internet connection." (Student 7)

"I was disappointed because my lecturer did not allow me to sign in the attendance. I forgot to do that because I was concentrating on the lecture." (Student 9) 
Technical support was also necessary to ensure smooth transition from onsite to online learning. Since the transformation from onsite to e-learning activities was very drastic, most of the students, particularly those who were lessexposed to digital technology, were not well prepared for the sudden shift. Thus, they could hardly cope with the technical difficulties. It is in these instances where it is important for the lecturers to provide the students with a tutorial on how to use specific technology which will be employed throughout the course. Assistance is also needed for them to learn how to access and work on their e-learning platform through the devices they used.

"I firstly (sic) was very confused of how to access our online learning. But, I got a tutorial in pdf on how to access our e-learning platform. That is very useful." (Student 9)

"I was so confused when we started the course. I think all of my friends felt the same as mine (sic). We were afraid of failure in our courses including English. Because the teaching was done online. Our lecturers used different technologies." (Student 3)

Online teaching indeed poses far greater challenges to teachers, as compared to onsite teaching. In the context of onsite learning activities, the teacher's preparation simply involves instructional planning and its execution through pedagogy and assessment. However, migrating onsite teaching to online activities require the teachers to do more. These include preparatory activities related to migrating the lesson online, engaging students with the appropriate learning environment, providing technical support and instilling the requisite technological skills.

\section{CONCLUSION}

The paper draws insights from a research that investigated university students' experiences of online learning through YouTube, in the context of a pandemic situation. The findings highlight the popularity of YouTube among the student participants. However, the prevalence of using YouTube for English language learning was not as frequent as that of learning other subjects and for entertainment. There is an opportunity to promote more ubiquitous English learning by employing YouTube to increase language exposure and student engagement in an authentic and interactive learning environment. YouTube features enable teachers to create and elaborate various innovations of synchronous and asynchronous learning activities. With this opportunity, the use of YouTube for learning English promotes quality learning processes. Ultimately, it encourages peer interaction, autonomous learning, and student-centered learning activities which are fundamental in developing the students' language skills. However, using YouTube in EFL education requires variability depending on specific needs and purposes of learning. Despite its magnificent features, teacher creativity plays an important role in attaining quality teaching and learning satisfaction.

\section{REFERENCES}

[1] J. Brook, "The Affordances of YouTube for Language Learning and Teaching," Hawaii Pacific University TESOL Working Paper Series, vol. 9, no. 1-2, 2011, pp. 37-56.

[2] K. Beatty, Teaching and Researching Computer-Assisted Language Learning, 2nd ed, Harlow: Pearson Education Limited, 2010

[3] P. Gruba, Computer Assisted Language Learning (CALL), in The Handbook of Applied Linguistics, A. Davies, C. Elder, Eds. Malden: Blackwell Publishing, 2004, pp. 623-648

[4] H. A. Jarvis and M. Achilleos, "From computer assisted language learning (CALL) to mobile assisted language use," The Electronic Journal for English as a Second Language, Vol. 16, No 4, 2013.

[5] G. Duman, G. Orhon and N. Gedik, "Research trends in mobile assisted language learning from 2000 to 2012," ReCALL, vol. 27, no. 2, pp. 197-216, 2014.

[6] A. Kukulska-Hulme and O. Viberg, "Mobile collaborative language learning: State of the art," British Journal of Educational Technology, vol 49, no 2, 2018, pp. 207-218. Doi:10.1111/bjet.12580

[7] A. Novawan, S. Aisyiyah, F. Wijayanti, A. H. Miqawati, and N. S. Indrastana, "Investigating students' MALL experience in light of an ecological perspective," Journal of English in Academic and Professional Communication, Vol. 5, No. 2, 2019, pp. 64-75

[8] R. Shadiev, W. Hwang, and Y. Huang, "Review of research on mobile language learning in authentic environments," Computer Assisted Language Learning, 2017.

[9] Omnicore Agency, "Youtube by the Numbers: Stats, Demographics \& Fun Facts," Last updated: Oct 28, 2020, available at: https://www.omnicoreagency.com/youtube-statistics/

[10] R. Godwin-Jones, "Emerging technologies. Digital Video Update: YouTube, Flash, High-Definition," Language learning and technology, vol. 11, no. 1, 2007, pp. 12-16.

[11] C. A. Mayora, "Using YouTube to Encourage Authentic Writing in EFL Classrooms," TESL Reporter, vol. 42, no. 1, 2009, pp. 1-12.

[12] J. Watkins and M. Wilkins," Using YouTube in the EFL Classroom," Language Education in Asia, vol. 2, no. 1, 2011

[13] J. M. Terantino, "Youtube for Foreign Languages: You Have to See This Video," Language Learning \& Technology, Vol. 15, No.1, 2011, pp. $10-16$

[14] C. Chien, Y. Huang, \& P. Huang,"YouTube Videos on EFL College Students' Listening Comprehension," English Language Teaching, vol. 13 , no. 6,2020

[15] M. H., Albahiri \& A. A. M. Alhaj, "Role of visual element in spoken English discourse: implications for YouTube technology in EFL classrooms," The Electronic Library, vol. 38, no. 3, 2020, pp. 531-544. https://doi.org/10.1108/EL-07-2019-0172 